To the Editor of The LANCET.

SIR,-I see in your last week's issue, under the heading of "New Inventions," an aspirator described, by Coxeter and Son, in which a brass cylinder is used instead of the usual glass one; it thus becomes identical with the combined stomach-pump and aspirator which I described in your journal more than a year ago, even to the small piece of glass tubing introduced into the suction-tube to see the character of the fluid. I have no objection to Coxeter and Son making any improvement they can on the instrument, but I do not think you ought to describe it as a "new invention."-I am, Sir, yours obediently,

AIFRED GODRICH, M.A., M.R.C.S., L.R.C.P., L.S.A. Fulham-road, Feb. 14th, 1874.

\section{THE UNIVERSITY OF DUBLIN.}

To the Editor of THE LANCET.

Sir,-On the advent of the Conservatives to power, it is expected that Dr. Ball, senior member of Parliament of this University, will be made Lord Chancellor of Ireland. If this takes place, I would suggest that it would be most desirable to bring forward, as a candidate for the vacant seat, some member of the medical profession who is a Dublin graduate. The legal profession has far too long held possession of both seats, and I am sure many outside our profession would support a candidate from among us, as many are rather tired of having their representation looked on merely as a means of advancement at the bar. All graduates in Medicine of Dublin University are bond-fide children of their Alma Mater, inasmuch as graduation in arts is required as absolutely necessary before proceeding to the degree in medicine. I believe that Dublin has a larger number of medical men in her constituency than any other university, and certainly than any other university with the same stringent laws as to graduation. Such being the case, I think it would be only fair that one of her two members should be a Doctor of Medicine, or at least Master in Surgery. I only throw out this hint hoping some action may be taken before a vacancy occurs.

I am, Sir, your obedient servant,

February 17th, 1874.

A Dublin Graduate.

\section{THE ELASTIC LIGATURE; A SUGGESTION.} To the Editor of THE LANCET.

SrR,-Having been engaged in the endeavour to find a better method of treating the pedicle in ovariotomy, it has occurred to me that the elastic ligature described by Sir H. Thompson in The LANCET for January 3rd supplies a material exactly suited for the purpose, being apparently free from the obstacles accompanying the use of any other plan. My personal experience of ovariotomy being limited thus far to two cases-one successful, the other fatal-and not likely to be rapidly multiplied, I have thought the above suggestion might possibly lead to its adoption by some one having a better opportunity of putting it to a speedy trial than,

Sir, your obedient servant,

Luton, Jan. 15th, 1874.

Ed. Woakm, M.D. Lond.

\section{ROYAL COLLEGE OF PHYSIOIANS.}

A MeETING of the Fellows was held on Thursday evening. After some preliminary business, a report of the Council, touchirg the repair of the College, was received, and it was resolved to issue a circular to the Fellows, asking for voluntary subscriptions towards that object. A memorial to the Prime Minister, setting forth the evils of overcrowding in different parts of London, inereased by the demolition of houses to make way for railroads, of late years, and asking for legislation on the subject, was adopted. The College subsequently discussed the Report of the Committee of Reference for an Examining Board for England. We shall notice some of these matters in detail next week.

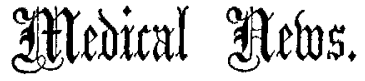

Indian Medical Service.-The following is a list of candidates who were successful at the competitive examinations held at London in August, 1873, and at Netley in February, 1874, after having passed through a course at the Army Medical School, Netley:-

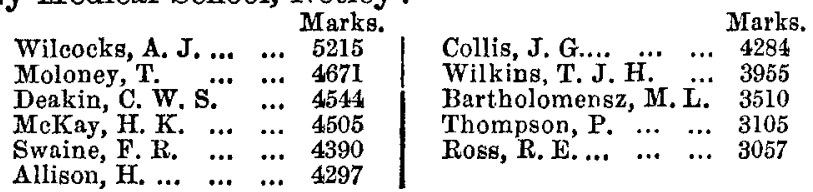

Apothecaries' Harr. - The following gentlemen passed their examination in the Science and Practice of Medicine and received certificates to practise on Feb. 5th and 12th: Hughes, Thomas Jones, East India Dock Road, Poplar. Lucas, Henry Owen, Highgate.

Power, George Edward, Ladywell, Lewisham.

Smith, Herbert Neale, Richmond Villa, Brighton

Symonds, Horatio Percy, Beaumont-street, Oxford.

The following gentleman passed his Primary Professional Examination on Feb. 12th :-

Hawkins, William, St. Thomas's Hospital.

Presentation.-Mr. John Fraser Weatherhead, who, through failing health, recently resigned the appointment of assistant medical officer to the City of London Lunatic Asylum, which he has held for nearly four years, was presented on bis retirement by the attendants and other employés of the institution with a handsome stationery cabinet, together with an address in which they expressed their regret at the separation which his departure occasioned.

Bequests \&c. To Medical Charities. - Lord Blayney has bequeathed $\$ 10,000$ to be divided among five Dublin charities. The Royal Free Hospital, Gray's-inn. road, has received a sixth $£ 1000$ from “D. G." The Metropolitan Free Hospital has received another $\$ 1000$ from “E. G. A." Mr. T. Brassey, M.P., has given 21000 towards enlarging the Hastings Infirmary. The London Hospital has received a sixth $\mathscr{\&} 1000$ from "E. F. H." The Asylum for Idiots, Earlswood, has received a sixth $\$ 1000$ from "N. C. K." The City Ortbopædic Hospital, Hatton-garden, has received $£ 1000$ from “C. O. H." The Seamen's Hospital Society has received $\$ 1000$ from “E. R." Mr. Greenall, the newly elected M.P. for Warrington, has given $£ 1000$ towards building a new hospital and dispensary for that town. The Middlesex Hospital has received another 21000 from "D. T. S." The Great Northern Hospital has received $\$ 1000$ from "S. W. Y."-Mr. T. W. Hill, of Clifton, has bequeathed $£ 5000$ and a share of the residue (expected to realise $\$ 50,000$ ) to the Bristol Royal Infirmary. $\$ 3000$ has been given anonymously among the medical charities of Glasgow and the immediate neighbourhood.

\section{atteoural Appointments.}

Alugr, W. H., L.R.C.P.Ed., L.R.C.S.Ed., has been appointed Parochial Medical officer and Public Vaccinator for Evie and Rendal, Urkney, vice Jefferiss.

Drki, D., M.R.C.S.E., has been appointed an Honorary District Surgeon to the Royal South London Dispensary, vice Sangster.

Duncarson, J. J. K., M.D., has been appointed Parochial Medical officer for the North-West Dist rict of Edinburgh.

Exzior, N. B., L.R.C.P.I., M.R.C.S.E., has been appointed a Medical officer to the Camberwell Provident Dispensary, vice Bringloe, resigned.

GalabIN, A. . ., M.A., M.D., M.R.C.P.L., has been appointed Assistant Obstetric Physician to Guy's Hospital, vice Phillips, deceased.

Gibings, A., M.R.C.S.E., L.D.S., has been appointed Dental House-Surgeon to the Dental Hospital of London, vice Rogers, resigned.

JoskPH, G. W., L.K Q.C.P.I., has been appointed Resident Surgeon and A pothecary to the Warrington Dispensary and Hatton's Charity Hospital, vice Barton, resigued.

LIDDFRDALB, J., M.R.C.S.E., has been appointed House-Surgeon to the Female Lock Hospital, Westbourne-green, vice Marshall, appointed Resident Registrar and Chloroformist, St. Mary's Hospital.

LUMLEY, B., M.R.C.S.E., has been appointed Medical Officer and Public Vaccinator for the Northallerton District of the Northallerton Union and the Workhouse, vice J. S. Walton, M.R.C.S.E., deceased.

M'DowaLL, T. W., M.D., L.R.C.S.Ed. (Assistant Medical Officer of the West Riding Lunatic Asylum, Wakefield), has been appointed Medical Superintendent of the Northumberland Lunatio Asylum, vice Wilson, deceased. 